\title{
O Papel da Modelagem Mental dos Enunciados na Resolução de Problemas em Física
}

The role of mental modelling of the statements in Physics problem solving

\author{
Sayonara Salvador Cabral da Costa \\ Faculdade de Física, PUCRS \\ Av. Ipiranga, 6681, 90619-900 Porto Alegre, RS, Brasil \\ sayonara@pucrs.br \\ Marco Antonio Moreira \\ Instituto de Física, UFRGS \\ Caixa Postal 15051, Campus do Vale, 91501-970, Porto Alegre, RS, Brasil \\ moreira@if.ufrgs.br
}

Recebido em 27 de novembro, 2000. Manuscrito revisado recebido em 14 de fevereiro, 2002.

Aceito em 24 de março, 2002.

\begin{abstract}
Este trabalho, fundamentado na Teoria dos Modelos Mentais de Johnson-Laird (1983, 1996), dá continuidade ao nosso projeto sobre modelagem mental em resolução de problemas (Costa e Moreira, 1998), enfocando a dificuldade que alunos de Mecânica Geral, disciplina do currículo básico dos cursos de Engenharia e Física da Pontifícia Universidade Católica do Rio Grande do Sul, apresentam para modelar mentalmente o enunciado do problema. Foi usada uma metodologia qualitativa baseada nos depoimentos verbais (durante aulas específicas de resolução de problemas) e escritos nas verificações de aprendizagem), de alunos das turmas de um dos autores, durante o período $1^{\circ}$ semestre de 1998 a $1^{\circ}$ semestre de 2000. O tema abordado foi Cinemática de um ponto material. Os resultados parecem corroborar nossa hipótese de que a representação mental do enunciado de um problema, apresentado através de um discurso lingüístico, acompanhado ou não de representação pictórica, pode ser favorecida pelo ensino explícito da modelagem física das situações enfocadas no enunciado.
\end{abstract}

This paper, based on Johnson-Laird's mental models theory (1983, 1996), is a sort of progress report of our project on mental modeling in problem solving, focusing on the difficulties that students of General Mechanics, a subject of the basic curriculum of engineering courses of the Catholic University of Rio Grande do Sul, present to mentally model the statement of the problem. A qualitative methodology was used based on students verbal (during problem solving classes) and written (in quizzes and exams) discourse, during the period of time between the first semester of 1998 and the first semester of 2000. The topic was Kinematic of a material particle. Research findings seem to support our hypothesis that the mental representation of the statement of a problem, presented through linguistic discourse, accompanied or not of a pictoral representation , might be facilitated by the explicit teaching of the physical modeling of the situations involved in that statement.

\section{Introdução}

A prática, difundida entre professores de Física (ao lado de outras disciplinas dos currículos de formação acadêmica), de privilegiar a atividade de resolução de problemas, é incontestável. Parece-nos, entretanto, que a justificativa, se nos fosse facultado consultar os professores, não seria tão consensual, ainda que todos apre- sentassem alguma razão para legitimar o seu uso.

Para nós, a atividade de resolver problemas é intrínseca ao processo de ensino-aprendizagem, podendo, inclusive, ser concebida como meio e/ou fim do mesmo. Para começar, consideramos um problema como uma situação na qual um indivíduo, uma vez tendo-a reconhecida como tal, necessita utilizar processos envolvendo reflexão, raciocínio e tomadas de de- 
cisões para seguir um caminho na busca de solucionála. Não acabamos de sintetizar o processo de aprendizagem? Pois aprender não é tomar conhecimento de alguma coisa, retê-la na memória, tornar-se apto ou capaz de alguma coisa, em conseqüência de estudo, observação, experiência, discernimento ? Aprender requer uma atitude de confronto com um problema para o qual não se tem, mas busca-se a resposta.

Nosso interesse em resolução de problemas tem nos ensejado uma relativa atualização a respeito de pesquisas desenvolvidas sobre o tema (Costa e Moreira, 1996; 1997a; 1997b; 1997c; Moreira e Costa, 2000). Desde 1997, estamos investigando a questão da modelagem mental dos enunciados dos problemas. Este trabalho dá seqüência a outros, sobre o mesmo tema (Costa e Moreira, 1998; 2000), na medida em que pretende investigar algumas dificuldades inerentes ao processo de resolução de problemas ( ou à aprendizagem de Física), mais especificamente a questão da interpretação dos enunciados dos problemas, envolvendo um domínio específico. Nosso objetivo é:

- identificar algumas características de dificuldades manifestadas por um número considerável de indivíduos no desenvolvimento da atividade de resolução de problemas;

- apresentar justificativas que possam corroborar a nossa hipótese de que é possível ensinar-se, no sentido de ajudar, a modelagem mental das situações representadas nos enunciados dos problemas.

Neste artigo desenvolvemos o primeiro objetivo que, na nossa opinião, pode constituir-se em um dos subsídios para o desenvolvimento de atividades de ensino visando facilitar a modelagem mental para os alunos.

A seguir, faremos algumas considerações sobre o tema da modelagem mental, tendo como referência a teoria dos Modelos Mentais de Johnson-Laird (1983). A metodologia utilizada, os resultados obtidos e a sua análise dará continuidade a este relato; por último, apresentaremos a conclusão, que reunirá comentários sobre possíveis inferências logradas a partir da conjugação da teoria disponível e resultados encontrados.

\section{Fundamentação teórica}

Modelos mentais são representações internas construídas pelas pessoas para captar o mundo exterior. Seres humanos entendem o mundo construindo modelos mentais, isto é, "modelos de trabalho" que predizem e explicam eventos.

O processamento da linguagem é um dos mais importantes domínios da aplicação da teoria de Modelos Mentais. O principal foco de atenção tem sido em como os modelos mentais são construídos quando os indivíduos entendem o que lêem ou o que é dito a eles. Nesse sentido, duas questões de pesquisa têm sido do- minantes: i) o que é representado e ii) o uso da memória de curto-prazo ( ou memória de trabalho) na construção do modelo mental.

Um princípio básico da Teoria dos Modelos Mentais considera que as representações mentais do conteúdo de textos são similares, em forma, às representações derivadas da percepção do mundo. Para Bransford (apud Garnham, 1997, p.154), a compreensão é um processo construtivo não só a partir do que está explícito no texto, mas da combinação desta com a informação armazenada na memória. Sob este aspecto, pode-se dizer que, ao construir o significado do texto, o indivíduo desenvolve um processo interpretativo.

O processo mental que dá coerência a esta interpretação é chamado inferência. Johnson-Laird (1983) considera dois tipos de inferências: i) as explícitas, que exigem um esforço consciente e deliberado para integrar a informação - como os que ocorrem durante os processos dedutivos presentes nas atividades científicas e ii) as implícitas, que sustentam os processos mais comuns e cotidianos de julgamentos como a compreensão do discurso, exigindo um conhecimento consciente mais superficial. A interação em sala de aula através da linguagem implica a geração e avaliação de inferências explícitas e implícitas entre as partes envolvidas.

Para compreender as premissas, são usados vários procedimentos semânticos, que permitem construir os modelos mentais. Construído o modelo mental de uma sentença, ele pode ser revisado, dependendo de novas informações. Nesse sentido, ele é provisório. Uma fonte de erro neste processo está relacionada com a conotação das palavras contidas nas premissas, que podem estar fora do alcance do indivíduo: os modelos mentais de uma pessoa estão limitados por fatores tais como seu conhecimento e sua experiência prévia com a terminologia utilizada, além da própria estrutura do sistema de processamento da informação, (Norman, 1983). Este último ponto será discutido a seguir.

O segundo domínio de aplicação da teoria dos Modelos Mentais está relacionado com o pensamento e o raciocínio. Neste âmbito, o enfoque é dado tanto para as representações presentes nestas atividades como para os processos que manipulam estas representações na memória de curto-prazo. Inclusive, a quantidade requerida de processamento e armazenamento nesta memória tem sido usada para explicar a dificuldade relativa de problemas aparentemente similares. Equívocos podem ser atribuídos à limitação da memória de trabalho - quanto mais modelos mentais se necessite para um problema que exige raciocínio, mais difícil ele resultará.

Estes modelos podem ser considerados como os tijolos na construção do conhecimento, mas eles só podem ser adequadamente utilizados se forem "manuseados" pelo raciocínio.

A Teoria dos Modelos Mentais pretende dar conta do raciocínio em geral, incluindo a inferência na com- 
preensão da linguagem, o raciocínio indutivo e, é claro, o dedutivo (incluindo o raciocínio silogístico). Segundo Johnson-Laird (apud Garnham, 1997, p.167), uma inferência indutiva é compatível com somente um dos modelos mentais construídos das premissas. Esta característica traz dificuldades para o indivíduo quando ele precisa escolher um modelo entre todos os compatíveis com as premissas. Por isso, alguns princípios vão reger o processo de indução: especificidade, parcimônia, uso de conhecimento prévio e disponibilidade de resgatar a informação da memória.

Como se pode ver até aqui, a Teoria dos Modelos Mentais tem uma aplicação "natural" para a resolução de problemas. Descrever como os indivíduos resolvem problemas é explicar como eles procuram por uma solução num espaço que pode conter uma infinidade de possíveis soluções ( como proposto originalmente por Newell e Simon, 1972). Este espaço usa a noção de representação de um estado de ações, portanto a de um modelo mental.

Recentemente (Garnham, 1997, p.168), a abordagem de modelos mentais para resolução de problemas tem enfatizado o uso do conhecimento prévio mais do que a busca através de um espaço de possibilidades. Mais uma vez, a noção de modelo mental é pertinente, uma vez que a tarefa requer a transformação da representação do mundo em função da incorporação de informações e experiências aos modelos mentais já existentes.

Continuaremos este trabalho descrevendo a metodologia empregada, seguida da apresentação e análise dos resultados obtidos, confrontando-os com a Teoria dos Modelos Mentais.

\section{Metodologia}

Prosseguindo com a pesquisa envolvendo os alunos da disciplina de Mecânica Geral, do currículo básico dos cursos de Engenharia e Física da PUCRS, descreveremos, nesta oportunidade, o trabalho desenvolvido com as turmas de um dos autores, no período entre $1^{\circ}$ semestre de 1998 e $1^{\circ}$ semestre de 2000 . O conteúdo que será objeto de análise é o do Movimento de um ponto material, desenvolvido no período de um mês, com seis horas de aulas semanais, divididas em dois encontros de três horas. Destes, cinco foram de apresentação e discussão do conteúdo, intercalados por dois exclusivos de resolução de problemas, culminando com um para revisão geral do tema e outro para a avaliação individual ou "prova" final sobre o conteúdo trabalhado. No total, foram utilizados 9 encontros.

Nossa metodologia de trabalho foi a análise qualitativa das manifestações verbais e escritas dos alunos durante as tarefas de resolução de problemas. Nas aulas exclusivas para esta atividade, os alunos, em cada semestre, recebiam uma lista de problemas. Trabalhando em pequenos grupos, de dois a quatro alunos (ver tabela 1), podiam solicitar a intervenção do professor para discutir a interpretação e/ou a abordagem de um determinado problema - ainda que alguns alunos, mais reservados, preferissem trabalhar e consultar individualmente o professor.

Na aula de revisão, os alunos tinham a oportunidade de manifestar individualmente suas dúvidas quanto a aspectos do conteúdo, referendados ou não por seus pares, veiculado ou não nos problemas propostos, além de solicitarem ajuda especificamente na resolução de alguns problemas. O professor aproveitava o momento para fazer uma abordagem "holística" do tema estudado, organizando e justificando seu desenvolvimento e os procedimentos requeridos na resolução de problemas. Ao final das aulas de resolução de problemas e da de revisão, perguntas e comentários dos alunos eram anotados. Os desempenhos nas avaliações individuais escritas acrescentaram dados sobre a "dinâmica" do processo.

Tabela 1. Dado sobre número de alunos e grupos aproximados no período da pesquisa.

\begin{tabular}{|l|c|c|c|c|c|}
\hline Semestre & I/1998 & II/1998 & I/1999 & II/1999 & I/2000 \\
\hline $\begin{array}{l}\text { N⿳ aproximado } \\
\text { grupos nas aulas } \\
\text { de R.P. }\end{array}$ & 12 & 7 & 9 & 10 & 9 \\
\hline $\begin{array}{l}\text { N⿳亠 de alunos na } \\
\text { verificação de } \\
\text { aprendizagem }\end{array}$ & 47 & 23 & 35 & 40 & 35 \\
\hline
\end{tabular}

A maioria dos problemas propostos eram oriundos da bibliografia indicada na primeira aula de cada semestre. Entre eles, Beer e Johnston (1991), Hibbeler (1985, 1999), Meriam e Kraige (1999) e Fonseca (1964). Os problemas eram escolhidos sob o critério de abrangerem uma gama considerável de situações em que as duas principais classes de conhecimento fossem requeri- das: o declarativo ou figurativo e o procedimental ou operativo (Sternberg, 2000, p.151).

$\mathrm{O}$ conhecimento declarativo consiste em conhecer "fatos". Por exemplo, que $\vec{v}=\frac{d \vec{r}}{d t}$ é a expressão que nos permite calcular a velocidade instantânea e que ela significa a derivada da posição em relação ao tempo. $\mathrm{O}$ conhecimento operativo ou procedimental, por sua vez, 
envolve conhecer a fonte do conhecimento declarativo como se sabe que $v=\frac{d \vec{r}}{d t}$ é a expressão da velocidade instantânea? - e a capacidade de usar, aplicar, transformar ou reconhecer a relevância do conhecimento declarativo em situações novas e não familiares (Arons, 1990).

No nosso entendimento, as atividades propostas contribuíam para o desenvolvimento desta capacidade, conjugando o raciocínio dedutivo e indutivo com a interpretação da observação e experiências pessoais. Concordamos com Zylbersztajn (1998) no que diz respeito à atividade de resolver problemas: "Estamos tratando com um processo concomitante e interdependente: ao mesmo tempo que a teoria é necessária para a resolução de problemas, ela também se refina e se aprofunda por meio da resolução de problemas, e o mesmo pode-se dizer dos procedimentos".

As modificações ocorridas na listagem dos problemas apresentados, no período da pesquisa, foram mínimas. Apenas dois deles foram substituídos com o propósito de expandir a apresentação de situações inéditas ou diferenciadas em formato das já trabalhadas em exemplos.

A primeira aula de problemas propunha situações envolvendo movimento em uma dimensão, apresentando-as através de funções matemáticas representando a posição, ou velocidade, ou aceleração (q.v. Anexo). O objetivo desta atividade é o domínio das relações entre as grandezas cinemáticas fundamentais e destas com outras secundárias, assim como os procedimentos para desenvolvê-las em conformidade com as condições específicas (condições de contorno) em cada problema. As situações apresentadas requerem que os alunos conjuguem o domínio dos conceitos em cinemática, presumivelmente já trabalhados em disciplinas anteriores, com o cálculo diferencial e integral e álgebra vetorial, também considerados como prérequisito.

A segunda aula de problemas abordou o movimento plano e tridimensional de um ponto. O objetivo permanecia o mesmo, ou seja o de dominar as relações entre as grandezas cinemáticas e os procedimentos para desenvolvê-las, em consonância com as condições específicas em cada problema. Esperavase, outrossim, que os processos desenvolvidos em uma dimensão fossem generalizados para duas e três dimensões, utilizando-se diferentes coordenadas (cartesianas, polares, intrínsecas). Entretanto, o sucesso desta atividade está condicionado também à concepção do que seja um vetor, do caráter vetorial das grandezas cinemáticas fundamentais, associado a procedimentos específicos para abordá-la. A análise deste tema, pela sua extensão, será objeto de um próximo trabalho.

Apesar de trabalharmos ao longo do período da pesquisa com os resultados parciais de cada semestre, e cada vez insistir na discussão de temas polêmicos ou que haviam suscitado muitos equívocos e dúvidas nos semestres anteriores, verificamos uma grande resistência a mudar este quadro com muitos alunos, que manifestavam os mesmos embaraços já detectados anteriormente.

O que os indivíduos pensam, os conhecimentos que eles trazem para uma tarefa cognitiva provê as estruturas de esquemas interpretativos que permitem raciocinar e levar adiante a resolução de problemas. Estas crenças, esquemas individuais de raciocínio, não são construções puramente individuais, são compartilhadas por uma "cultura social." (Resnick, 1994, p. 477). A forma como os grupos de alunos desenvolveram as atividades ao longo dos semestres reflete uma abordagem relativamente constante na questão de resolver problemas: um trabalho quase mecânico.

Esta constatação serviu para ratificar nossa hipótese de trabalho de que a interpretação deste tipo de problemas não é tarefa fácil para os alunos; a falta de uma modelagem mental adequada gera obstáculos de níveis diversos, todos concorrendo para a inviabilidade da solução dos problemas. Neste trabalho apresentaremos algumas regularidades, manifestadas pelos alunos ao resolverem problemas de uma lista e uma questão da prova escrita de avaliação, que reforçam nosso ponto de vista.

\section{Apresentação/ análise dos re- sultados}

Problema 1 - Lista 1

O movimento de um ponto material é
descrito pela função $x=t^{4}-3 t^{3}+t$, onde
$x$ é dado em metros e $t$ em segundos.
Determinar a posição, a velocidade e a
aceleração quando $t=2 s$.

Apesar de ser considerado por nós o problema mais simples, praticamente um "exercício", que ensejaria o uso das relações entre posição, velocidade e aceleração, surpreendemo-nos com algumas reações de alunos (repetidas em todos (!) os semestres).

Um número expressivo de alunos (tabela 2) tentou "integrar" a função horária da posição para descrever a velocidade - na discussão com eles, este procedimento evidenciou que não haviam identificado a informação do problema: a função horária da posição. As relações $v=\frac{d x}{d t}$ e $a=\frac{\mathrm{dv}}{\mathrm{dt}}$ foram "lembradas", escritas inclusive, mas os alunos não souberam como utilizá-las; parece que o significado delas não foi apreendido. Por outro lado, este foi o primeiro problema que teriam que resolver sozinhos, e esta aula sucedeu outra na qual se discutiram e se exemplificaram alguns movimentos descritos através de suas acelerações. Nestes casos, para 
obter-se a velocidade instantânea, necessitava-se integrar a função da aceleração. Consideramos que este fato corroborava nossa suposição acima grifada, ou seja, no nosso entendimento, os alunos não representaram internamente, em termos de um modelo mental da situação, as informações contidas no enunciado e reagiram de forma mecânica, seguindo os últimos procedimentos utilizados nos exemplos. Portanto, o primeiro requisito para representar internamente o enunciado falhou. A falta do reconhecimento e do domínio do formalismo matemático necessário para realizar a tarefa - registrado por escrito, sem demonstrar que tenha sido compreendido - inviabilizaram o processo. Uma pergunta feita por um aluno, mesmo depois de havermos discutido com o seu grupo, que apresentara dificuldades com este problema, retrata bem o que estamos querendo dizer: "Para calcular a posição quando $t=2 s$, então é só substituir na função de x?"

Tabela 2. Dado sobre número de alunos e grupos aproximados no período da pesquisa.

\begin{tabular}{|l|c|c|c|c|c|}
\hline Semestre & I/1998 & II/1998 & I/1999 & II/1999 & I/2000 \\
\hline $\begin{array}{l}\text { N⿳ aproximado de alunos } \\
\text { presentes na aulas de R.P. }\end{array}$ & 41 & 22 & 32 & 35 & 31 \\
\hline $\begin{array}{l}\text { N⿳ de alunos que } \\
\text { expressaram } \\
\text { dificuldades no problema 1 }\end{array}$ & $\begin{array}{c}5 \\
(12 \%)\end{array}$ & $\begin{array}{c}3 \\
(23 \%)\end{array}$ & $\begin{array}{c}4 \\
(12,5 \%)\end{array}$ & $\begin{array}{c}4 \\
(11,5 \%)\end{array}$ & $\begin{array}{c}4 \\
(13 \%)\end{array}$ \\
\hline
\end{tabular}

\section{Problema 2 - Lista 1}

A relação $x=t^{3}-12 r^{3}+45 t+18$ (S.I.) representa a posição de um ponto material em
função do tempo. Determinar a: o instante para o qual a velocidade se anula; b) a
posição, a aceleração e a distância percorrida ao fim de $5 \mathrm{~s}$.

A experiência do problema anterior e a discussão que provocou parecem ter surtido efeito pois, neste caso, não se verificaram as dificuldades manifestadas no primeiro problema. "Quando os indivíduos movem-se de uma situação para outra, carregam histórias de experiências prévias com eles. São histórias de formas de agir... situações similares experimentadas transferem conhecimento, nem sempre o correto...." (ibid., p.490). Por outro lado, o significado da relação apresentada no enunciado era explícito. Mesmo sem podermos avaliar individualmente as causas, aqui os alunos usaram corretamente as relações entre a posição, a velocidade e a aceleração instantâneas, bem como souberam calcular o instante em que a velocidade se anulava. Em compensação, TODOS os que tiveram dúvidas (tabela 3), revelaram-nas em algum destes aspectos:

- Como calcular a distância percorrida?

- Por que analisar os deslocamentos parciais?

- Por que somar os módulos das integrais?

Tabela 3. Percentagem de alunos que manifestaram dificuldades no problema 2, por semestre.

\begin{tabular}{|c|c|c|c|c|c|}
\hline Semestre & I/1998 & II $/ 1998$ & I/1999 & II $/ 1999$ & I/2000 \\
\hline & $\begin{array}{c}22 \% \\
(9 \text { alunos })\end{array}$ & $\begin{array}{c}23 \% \\
(9 \text { alunos })\end{array}$ & $\begin{array}{c}25 \% \\
(9 \text { alunos })\end{array}$ & $\begin{array}{c}20 \% \\
(9 \text { alunos })\end{array}$ & $\begin{array}{c}16 \% \\
(9 \text { alunos })\end{array}$ \\
\hline
\end{tabular}

Estas questões parecem evidenciar a não-modelagem mental do conceito de distância e, conseqüentemente, das possíveis estratégias para obtêla, como calcular a integral da função velocidade em relação ao tempo, levando em consideração a mudança no sentido da velocidade. Se o significado da integração fosse entendido, facilitaria a compreensão da estratégia utilizada no cálculo da distância, reforçando, inclusive, o conceito desta. No caso de um movimento unidimen- sional, o aluno poderia determinar esta distância calculando a posição máxima atingida, o que permitiria obter o comprimento percorrido no intervalo de tempo considerado. O fracasso nesta tarefa já foi identificado por Gil Pérez et al. (1988), justamente creditando-o à falta de uma análise mais profunda da questão proposta.

Antevendo a dificuldade com o conceito e cálculo da distância percorrida, propusemos esta atividade em 
outro problema, impondo uma nova abordagem:

\section{Problema 3 - Lista 1}

Uma partícula se move ao longo de uma linha horizontal tal que sua velocidade é dada
por $v=\left(3 t^{2}-6 t\right) \mathbf{m} / \mathbf{s}$, onde $t$ é o tempo em segundos. Se a partícula está inicialmente
localizada na origem $\mathbf{0}$, determine: a) a distância percorrida desde $t=0$ até $t=3,5 \mathrm{~s} ; \mathbf{b})$
a velocidade média e escalar (modular) média durante o mesmo intervalo de tempo; $\mathbf{c})$
a aceleração instantânea em $t=3,5 \mathrm{~s}$. Interprete todos os resultados com suas próprias
palavras.

Neste problema, o aluno deveria tomar decisões sem que estivessem presentes no enunciado orientações explícitas: precisava investigar se havia inversão do sentido do movimento no intervalo de tempo escolhido para determinar a distância percorrida; só então ele teria condições de resolvê-lo. Com este procedimento ele evidenciaria a compreensão do modelo físico-conceitual apropriado. Foi mais fácil reconhecerem esta estratégia do que calcular os valores das velocidades médias, cujas definições estavam esquecidas (ver tabela 4). A inclusão de questões interpretativas dos resultados numéricos teve um resultado inesperado: raríssimos foram os alunos que pediram ajuda para discutir este item em todos os semestres avaliados! Uma observação que deve ser feita é que este tipo de item não tinha a sua resposta no final dos problemas da lista, como os outros com respostas numéricas. Desconhecemos se algum aluno, individualmente, tenha completado a solução do problema respondendo esta questão fora das aulas. Aparentemente eles consideravam-na "feita", pois quando diferentes grupos eram indagados se tinham dúvidas, respondiam negativamente. No primeiro semestre desta pesquisa, não demos muita importância para este comportamento, mas fomos surpreendidos pelo mesmo procedimento dos alunos nos semestres seguintes. Mesmo este tema, o da interpretação, tendo sido objeto de discussão nas aulas teóricas, esta reação persistiu ao longo do período deste trabalho.

Tabela 4. Número de alunos (ou grupos) que manifestaram dificuldades em cada semestre.

\begin{tabular}{|c|c|c|c|c|c|}
\hline \multicolumn{1}{|c|}{ Demestre } & $\mathrm{I} / 1998$ & $\mathrm{II} / 1998$ & $\mathrm{I} / 1999$ & $\mathrm{II} / 1999$ & $\mathrm{I} / 2000$ \\
\hline $\begin{array}{c}\text { Investigar mudança de sentido do } \\
\text { movimento. }\end{array}$ & $\begin{array}{c}7,3 \% \\
(3 \text { alunos })\end{array}$ & $\begin{array}{c}9 \% \\
(2 \text { alunos })\end{array}$ & $\begin{array}{c}6 \% \\
(2 \mathrm{alunos})\end{array}$ & $\begin{array}{c}9 \% \\
(3 \text { alunos })\end{array}$ & $\begin{array}{c}3 \% \\
(1 \text { aluno })\end{array}$ \\
\hline $\begin{array}{c}\text { Calcular a distância percorrida no no } \\
\text { intervalo considerado. }\end{array}$ & $\begin{array}{c}12 \% \\
(5 \text { alunos })\end{array}$ & $\begin{array}{c}14 \% \\
(3 \text { alunos })\end{array}$ & $\begin{array}{c}9 \% \\
(3 \text { alunos })\end{array}$ & $\begin{array}{c}11 \% \\
(4 \text { alunos })\end{array}$ & $\begin{array}{c}10 \% \\
(3 \text { alunos })\end{array}$ \\
\hline $\begin{array}{c}\text { Calcular as velocidades } \\
\text { médias. }\end{array}$ & $\begin{array}{c}17 \% \\
7 \text { alunos })\end{array}$ & $\begin{array}{c}18 \% \\
(4 \text { alunos })\end{array}$ & $\begin{array}{c}16 \% \\
(5 \text { alunos })\end{array}$ & $\begin{array}{c}11 \% \\
(4 \text { alunos })\end{array}$ & $\begin{array}{c}6,5 \% \\
(2 \text { alunos }) \\
1\end{array}$ \\
\hline $\begin{array}{l}\text { Interpretar com palavras os } \\
\text { resultados numéricos. }\end{array}$ & $\begin{array}{c}2 \% \\
(1 \text { aluno })\end{array}$ & $\begin{array}{c}4 \% \\
(1 \text { aluno })\end{array}$ & $\begin{array}{c}0 \% \\
\text { nenhum }\end{array}$ & $\begin{array}{c}0 \% \\
\text { nenhum }\end{array}$ & $\begin{array}{c}3 \% \\
(1 \text { aluno })\end{array}$ \\
\hline
\end{tabular}

A interpretação, "com as próprias palavras do aluno", suscita uma discussão particular, pois envolve a relação entre a linguagem falada habitualmente e a aceita cientificamente. Por um lado, o aluno não gosta de se expressar, por outro, o desenvolvimento e uso da linguagem desempenham um papel fundamental no ensino e aprendizagem. No que se refere à ciência, um dos aspectos que nos chama mais a atenção é a definição operacional de conceitos básicos.
As palavras adquirem significado através da experiência compartilhada. Segundo Arons (1990), "[palavras](...) são metáforas, extraídas do discurso do dia-a-dia, para o qual damos um significado profundamente alterado(...).". Os alunos não percebem isso a não ser que lhes apontemos explicitamente. Por isso é tão importante que os encorajemos a interpretar verbalmente os resultados numéricos e gráficos que eles obtêm. 
Alguns exemplos de situações evidenciadas durante o período da pesquisa podem ajudar a reforçar esta tese. É o caso do desempenho de muitos alunos na questão seguinte, proposta na verificação de avaliação em I/1998 e repetida com pequenas variações em II/1999 e I/2000:

\section{Questão de prova $-1^{\circ}$ semestre de 1998 e de 2000 e $2^{\circ}$ de 1999}

O movimento de um ponto material é definido pela relação $x=2 r^{3}-40 t^{2}+200 t-50$, em unidade do S.I.. a) Exatamente, qual é a informação que esta equação nos fornece?; b) Determine o(s) instante(s) em que a velocidade do ponto se anula. (fisicamente falando, o que está acontecendo ao movimento do ponto neste(s) momento(s)? Faça um comentário que justifique a sua resposta; c) Determine a posição, a aceleração e a distância percorrida pelo ponto ao fim de $5 \mathrm{~s}$. Interprete cada um destes resultados obtidos, ou graficamente, ou através de palavras.

- os conceitos de posição, deslocamento, trajetória e distância percorrida são freqüentemente confundidos pelos alunos. Foi o que aconteceu nas respostas para o item a). Por exemplo:

"Esta equação nos fornece a trajetória ${ }^{1}$ em um certo tempo, não é a distância percorrida" (ALUNO 4 1998)

"Ela nos determina o caminho de $x$ em função do tempo, ou seja, para cada tempo teremos uma posição diferente em nosso gráfico" (ALUNO 13-1998)

"Informa que a distância que um ponto material percorre é uma função do tempo, ou seja, a cada tempo existe uma distância diferente." (ALUNO 33-1998)

Nossa interpretação às respostas destes alunos não deixa de constituir-se em modelos mentais do que nós presumimos que eles tenham entendido. Segundo Johnson-Laird (1990), a linguagem nos capacita para ter experiência do mundo e para comunicar certas concepções abstratas dele. Um modelo mental representa o estado de coisas concretas a que se refere uma oração; lembrando-se que a comunicação humana depende de intenções, o significado de um comentário pode estar fora do alcance do ouvinte. De qualquer forma, a terminologia aceita cientificamente não coincide com a utilizada pelos alunos. Esta observação vale igualmente para os próximos desempenhos.

- a representação gráfica equivocada dos movimentos, objeto de estudo da literatura (p. ex. McDermott et al., 1986), foi retratada nos gráficos posição versus tempo, concebidos como a representação da trajetória do ponto.

"[a equação dada]...nos informa a forma do movimen to , que neste caso é uma parábola de terceiro grau...." (ALUNO 35-1999)

"No instante $t=5 \mathrm{~s}$, a posição do ponto é $200 \mathrm{~m} \mathrm{em}$ relação ao seu ponto de partida. Por exemplo: (ALUNO 28-1998)

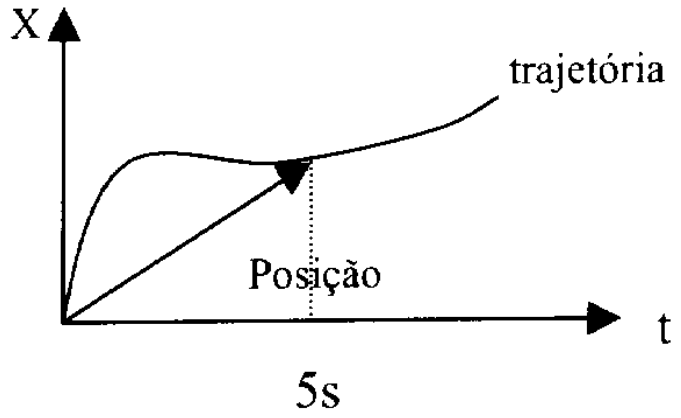

- Apesar de a maioria dos alunos identificar corretamente a função $\mathrm{x}(\mathrm{t})$, a noção de instante (inicial, final, qualquer) é confundida com a de intervalo de tempo:

"A equação nos dá a posição que um móvel está em um certo intervalo de tempo." (MLW-2000)

"Esta equação quer dizer a posição que o objeto se encontra em cada intervalo de tempo. (ALUNO 211999)

- A interpretação dos símbolos usados para designar as grandezas também mostra-se ambígua: na função horária da posição, há uma tendência "natural" de interpretar x como distância e t como tempo de duração. Na determinação da posição do ponto após $5 \mathrm{~s}$ (item c):

" $x(t=5 s)=2.5^{3}--40.5^{2}+200.5-50=$ $200 m$

$O$ ponto se encontra na distância de $200 \mathrm{~m}$ no instante de 5s." (ALUNO 1-1998)

Este resultado indica que foi percorrido $200 \mathrm{~m} \mathrm{em}$ 5s. (aluno 20-1998)

- Os conceitos de velocidade média e instantânea são confundidos; o mesmo acontece com a aceleração. Quando interpretam a velocidade instantânea, fazemno assim: "...o ponto anda tantos metros por segundo....". Trowbridge e McDermott (1980) já assinalavam a dificuldade de interpretar a velocidade (e, neste caso, também a aceleração) instantânea “...como um número, referindo-se a um único instante é uma

\footnotetext{
${ }^{1}$ Todos os grifos nas respostas dos alunos são de nossa autoria.
} 
barreira conceitual para muitos alunos" (p.1024). Os alunos tendem a utilizar muito a expressão "velocidade por tempo " para caracterizar a aceleração ou, "mudança de velocidade sobre tempo". Nesta última, sobre é usado no sentido de durante muito mais do que de razão, sem a percepção explícita da conexão com a unidade do intervalo de tempo. Alguns exemplos sobre a interpretação da aceleração em $\mathrm{t}=5 \mathrm{~s}$, dos poucos alunos que tentaram fazê-la:

"O ponto está sendo acelerado $6 \mathrm{~m} / \mathrm{s} / \mathrm{s}^{2}$. Graficamente, isto significa (ALUNO 3-1999):

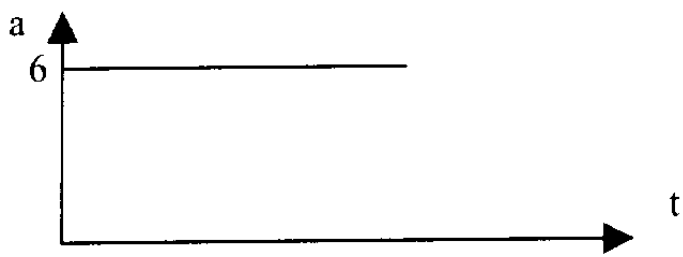

"Sua aceleração é de $6 \mathrm{~m} / \mathrm{s}$ neste segundo". (ALUNO7-1999)

"Significa que no instante escolhido, a velocidade do ponto aumenta $6 \mathrm{~m} / \mathrm{s}$ a cada segundo". (ALUNO 16-1999)

Nos três semestres, a maioria dos alunos simplesmente calculou a aceleração (tabela 5). Os que a interpretaram o fizeram como se a aceleração permanecesse constante no movimento, ou não conseguiram se expressar adequadamente, como mostram os exemplos acima. Estes resultados corroboram o trabalho de Trowbridge e McDermott (ibid.), no qual um aluno se manifesta sobre este tema da seguinte forma: “... para a velocidade ser calculada deve haver um intervalo de tempo. Para um instante os objetos não têm velocidade, só uma localização". Em Trowbridge e McDermott (1981) e Rosenquist e McDermott (1987) este tema é revisto, mas, no que diz respeito à aceleração instantânea, só é enfocado o movimento com aceleração constante.

- Condições para inversão no sentido do movimento são confundidas: termos como pára ou atinge o repouso momentaneamente, são expressões que devem ser evitadas neste caso, pois os alunos interpretam-nas como "permanece assim por um intervalo de tempo e assim a aceleração só pode ser zero".

A condição concomitante de velocidade nula e aceleração não-nula não é sequer assinalada pelos alunos como relevante na inversão do sentido do movimento.

"Para tempos em 3,3s e 10 s a velocidade se anula, ou seja, o ponto pára o seu movimento naqueles instantes." (ALUNO 35-1998)

"Isto significa que o objeto nos instantes $3,3 \mathrm{~s}$ e $10 \mathrm{~s}$ está parado, sem movimento em qualquer direção." (ARF-2000)

O registro das ambigüidades encontradas nas questões interpretativas do problema pode ser considerado um indicativo da dificuldade de os alunos expressarem suas concepções explicitamente. Por outro lado, estas questões constituem-se em um meio de avaliarmos as representações mentais dos alunos. Na primeira versão deste problema ( $1^{\circ}$ semestre de 1998), cerca de 14 alunos, num total de 47 , interpretaram a função no enunciado como representando a distância percorrida, enquanto 13 analisaram o instante em que a velocidade se anulava como se o movimento se interrompesse a partir daí, sem relacionar com a aceleração. Esta constatação ajudou-nos a discutir o fato nos semestres seguintes, tanto nas apresentações em aula como nas aulas específicas de problemas. Mesmo assim, estas concepções continuaram acontecendo. A tabela 5 acrescenta outros dados sobre o desempenho dos alunos nesta questão, nos três semestres envolvidos.

Tabela 5. Desempenho insatisfatório nas questões interpretativas em cada semestre.

\begin{tabular}{|c|c|c|c|}
\hline & $\mathrm{I} / 1998$ & II/1999 & $\mathrm{I} / 2000$ \\
\hline Questões interpretativas & & & \\
\hline Significado da equação $x=f(t)$ & $10,6 \%$ & $12,5 \%$ & $3 \%$ \\
\hline $\begin{array}{r}\text { Significado fisico no instante em que v = 0: interpretação incorreta } \\
\text { não interpretaram }\end{array}$ & $\begin{array}{l}28 \% \\
15 \%\end{array}$ & $\begin{array}{r}25 \% \\
5 \%\end{array}$ & $\begin{array}{r}15 \% \\
0 \%\end{array}$ \\
\hline Interpretação dos resultados numéricos: $\underline{\text { Posição : incorreta }}_{\text {não interpretaram }}$ & $\begin{array}{l}25,5 \% \\
21 \%\end{array}$ & $\begin{array}{l}30 \% \\
27,5 \%\end{array}$ & $\begin{array}{r}6 \% \\
46 \%\end{array}$ \\
\hline $\begin{array}{l}\text { Aceleração: incorreta } \\
\text { não interpretaram }\end{array}$ & $\begin{array}{l}19 \% \\
79 \%\end{array}$ & $\begin{array}{l}30 \% \\
65 \%\end{array}$ & $\begin{array}{l}11 \% \\
86 \%\end{array}$ \\
\hline $\begin{array}{l}\text { Distância percorrida: incorreta } \\
\text { não interpretaram }\end{array}$ & $\begin{array}{l}21 \% \\
17 \%\end{array}$ & $\begin{array}{l}27,5 \% \\
17,5 \%\end{array}$ & $\begin{array}{r}9 \% \\
60 \%\end{array}$ \\
\hline
\end{tabular}

\footnotetext{
${ }^{2}$ Este valor para a aceleração é o correto, de acordo com a função apresentada na primeira verificação em 1999/II.
} 
"Não interpretaram" significa que as respostas numéricas não foram traduzidas em palavras ou em outro tipo de representação, como diagramas. Por exemplo, uma resposta típica desta classificação para a interpretação do valor numérico da distância percorrida:

"29 $m$ é a distância percorrida ao fim de $3 s$ ". (Aluno 1 - 1999)

Como se vê, o aluno simplesmente repetiu a informação que se pedia, não explicou o que significava aquele resultado numérico para o movimento. Um exemplo de expressão incorreta para a mesma "distância percorrida" é a resposta de outro aluno:

“... 29m foi o que o ponto se deslocou em 3s." (Aluno 45 - 1998)

Aqui o deslocamento é tratado como distância percorrida. Novamente podemos pensar que talvez o aluno tenha se expressado mal, utilizado deslocamento para representar o comprimento do que foi percorrido. Mas a diferença é destacada em aulas de Física, e ele está sendo avaliado sob este ponto de vista.

Muitas investigações encontradas na literatura refletem o hiato entre os "conceitos intuitivos" e os modelos conceituais apresentados pelos livros e em sala de aula (e.g., Trowbridge e McDermott, apud Arons, 1990, p. 38). Devemos estar cientes de que, por mais lucidez que empreguemos em nossas apresentações, por mais que tenhamos proposto atividades variadas de resolução de problemas, isso não revelará o verdadeiro estado de compreensão e raciocínio dos nossos alunos. Também a compreensão dos alunos do que significa interpretar, explicar ou justificar algum fato é diferente da que esperaríamos; uma característica evidenciada pelas suas respostas é a superficialidade, o que pode estar evidenciando ou uma fragilidade de seus modelos mentais ou um despreparo de lidar com este tipo de exigência que aliás poderia ser confirmado pela reação nas aulas em que a interpretação escrita (problema 3) ou gráfica (problema 6) foi requerida e eles não se manifestaram. No nível deste curso, voltado para a aplicação de modelos físicos e matemáticos, poderíamos esperar que a questão conceitual estivesse resolvida, levando-se em conta a experiência em disciplinas anteriores de Física. Em princípio, o formalismo matemático aplicado e sua interpretação é que poderiam gerar maiores obstáculos à construção de um modelo mental que representasse e permitisse buscar uma solução para os problemas propostos - ainda que os conceitos e aplicações deste formalismo já tenham sido explorados em disciplinas específicas de Matemática.

Os demais problemas propostos na lista 1 (q.v. Anexo) apresentaram reações onde o aspecto mais dissonante da resolução correta foi a não observância das condições de contorno do problema (ou limites de integração das integrais). À medida que o número de integrais aumenta, parece que há uma tendência de generalização com respeito a estas condições: o fato de a maioria dos problemas envolver informações sobre as condições cinemáticas iniciais $(\mathrm{t}=0)$ provoca uma falta de atenção do leitor, um relaxamento nos dados determinantes, fazendo que o problema proposto seja mal identificado e, desta forma, tenha a sua resolução inviabilizada.

Na nossa opinião, este é o caso típico de erro devido à sobrecarga da memória de trabalho: muitas informações relevantes que devem ser consideradas, ao lado de estratégias não menos importantes que devem ser executadas.

Na mesma linha de raciocínio, situações mais concretas parecem favorecer a modelagem mental. No problema 5, os alunos, em geral, demonstraram saber como as informações os levariam ao objetivo almejado. As dificuldades aconteceram no desenvolvimento da estratégia, principalmente no cálculo da integral como um dos movimentos era uniformemente variado, era fácil a obtenção da função horária da posição, o que não acontecia para o outro, cuja operação, apesar de conhecida, não foi reconhecida por muitos; o uso indevido dos limites de integração também foi manifestado. Percebe-se que muitos alunos ainda insistem em ignorar a importância das condições específicas do problema; neste ponto a modelagem mental não é completa. Esta aparente relutância em não considerálas relevantes pode ser atribuída igualmente a uma "economia cognitiva", característica dos modelos mentais construídos pelos indivíduos ao reconhecerem uma tarefa, que provoca o fracasso quando muitos elementos de abstração são requeridos. Isso poderia justificar a relativa dificuldade com a interpretação do problema 6 , onde a principal informação estava no final do enunciado, o que fez que alguns alunos quase não a reconhecessem, devido à quantidade de informações contida nele. Novamente a representação gráfica, que ensejaria uma discussão sobre o comportamento do movimento, foi menosprezada pelos alunos. A não-observância de um mesmo sistema de unidades para as grandezas foi motivo de erro. Este problema foi incluído a partir do $2^{\circ}$ semestre de 1999.

No problema 7 , os limites de integração no cálculo da distância percorrida foram utilizados indevidamente pois, ao invés de levarem em conta o intervalo de tempo até o momento em que a aceleração se anulava, consideraram-no até o momento em que a velocidade se anulava. A representação incorreta de alguns alunos poderia ser atribuída a alguma ambigüidade do enunciado, mas nossa hipótese é que a condição de velocidade nula tenha sido confundida com a de aceleração nula dois momentos distintos do movimento.

No problema 8, nem todos se deram conta de que bastava encontrar a relação entre a velocidade e a posição para responder às duas perguntas. Achavam que para calcular a posição deveriam "integrar" novamente, como era "hábito" fazer em outras ocasiões. Esta falta de atenção à totalidade do enunciado denota 
uma leitura descompromissada com a interpretação do que lêem.

A condição apresentada no problema 9 é inusitada: a velocidade é representada como uma função do deslocamento. Os alunos deveriam ultrapassar o conhecimento requerido até então, ser criativos, resgatando uma condição que tinha sido explorada em aulas teóricas em um contexto diferente, ou seja, "a regra da cadeia": precisariam avançar no uso da derivada de uma função cuja variável de integração não era explícita. Uma vez ultrapassada esta "barreira", o procedimento seguinte não apresentou dúvidas. Mas, sem este discernimento inicial da situação apresentada, com seus conceitos e procedimentos inerentes, a resolução estaria inviabilizada (é importante lembrar que resolução é entendida como o processo que se inicia pela clarificação do enunciado, sua relação com um conhecimento prévio que possibilite seu desenvolvimento). Como essa questão não chegava a ser realizada em aula, por uma questão de tempo, era a última da lista, muitos eram os alunos que pediam ajuda para resolvê-la, individualmente, ou no máximo em duplas, pela mesma razão: não conseguiam atinar com o "gatilho" para a sua resolução.

A tabela 6 apresenta um resumo das dificuldades que os alunos manifestaram na aula de resolução de problemas para os problemas 4 a 9 e a percentagem de consultas ao professor em cada semestre.

Tabela 6. Dificuldades manifestadas por alunos (grupos) nos problemas 4 a 9 da Lista 1.

\begin{tabular}{|c|c|c|c|c|c|}
\hline Total de alunos & $\begin{array}{l}1 / 98 \\
41 \\
\end{array}$ & $\begin{array}{c}\text { II } / 98 \\
22 \\
\end{array}$ & $\begin{array}{r}1 / 99 \\
32 \\
\end{array}$ & $\begin{array}{r}\mathrm{II} / 99 \\
35 \\
\end{array}$ & $\begin{array}{l}\mathrm{I} / 00 \\
31\end{array}$ \\
\hline \multirow[t]{3}{*}{$\begin{array}{lll}\begin{array}{l}\text { Observância } \\
\text { contorno: }\end{array} & \text { das } & \text { condições de } \\
& & \text { (problema 4) }\end{array}$} & $\begin{array}{c}12 \% \\
\text { (5 alunos) }\end{array}$ & $\begin{array}{c}14 \% \\
(3 \text { alunos) }\end{array}$ & $\begin{array}{c}12,5 \% \\
\text { (4 alunos) }\end{array}$ & $\begin{array}{c}8,6 \% \\
\text { (3 alunos) }\end{array}$ & $\begin{array}{c}6,5 \% \\
\text { (2 alunos) }\end{array}$ \\
\hline & $\begin{array}{c}12 \% \\
\text { (5 alunos) }\end{array}$ & $\begin{array}{l}14 \% \\
(3 \text { alunos })\end{array}$ & $\begin{array}{c}9,5 \% \\
\text { (3 alunos) }\end{array}$ & $\begin{array}{c}8,6 \% \\
\text { (3 alunos) }\end{array}$ & $\begin{array}{c}6,5 \% \\
\text { (2 alunos) }\end{array}$ \\
\hline & $\begin{array}{c}7,3 \% \\
\text { (3 alunos) }\end{array}$ & $\begin{array}{l}9 \% \\
\text { ( } 2 \text { alunos) }\end{array}$ & $\begin{array}{c}9,5 \% \\
\text { (3 alunos) }\end{array}$ & $\begin{array}{c}8,6 \% \\
(3 \text { alunos }) \\
\end{array}$ & $\begin{array}{c}3,2 \% \\
\text { (1 aluno) } \\
\end{array}$ \\
\hline $\begin{array}{r}\text { Representação do enunciado } \\
\text { (problema 6) }\end{array}$ & - & - & - & $\begin{array}{c}20 \% \\
(7 \text { alunos })\end{array}$ & $\begin{array}{c}13 \% \\
(4 \text { alunos) }\end{array}$ \\
\hline $\begin{array}{l}\text { Cálculo da posição } \\
\text { (problema 8) }\end{array}$ & $\begin{array}{c}12 \% \\
\text { (5 alunos) }\end{array}$ & $\begin{array}{c}14 \% \\
(3 \text { alunos })\end{array}$ & $\begin{array}{c}9,3 \% \\
(3 \text { alunos }) \\
\end{array}$ & $\begin{array}{c}8,6 \% \\
(3 \text { alunos }) \\
\end{array}$ & $\begin{array}{c}6,5 \% \\
(2 \text { alunos }) \\
\end{array}$ \\
\hline $\begin{array}{llll}\text { "Gatilho" para } & \text { resolver } & 0 \\
\text { problema } 9 & & & \end{array}$ & $\begin{array}{c}29 \% \\
\text { (12 alunos) }\end{array}$ & $\begin{array}{c}23 \% \\
\text { (5 alunos) }\end{array}$ & $\begin{array}{c}25 \% \\
\text { (8 alunos) }\end{array}$ & $\begin{array}{c}23 \% \\
\text { (8 alunos) }\end{array}$ & $\begin{array}{c}16 \% \\
\text { (5 alunos) }\end{array}$ \\
\hline
\end{tabular}

Essas dificuldades, manifestadas periodicamente, nos incitam a refletir sobre os processos mentais individuais e em grupo. Em média, os grupos chegavam a fazer em aula até os problemas 5 ou 6 . Estes tiveram a oportunidade de serem "negociados" em cada grupo, ou seja, alguém propunha uma solução e os outros seguiam-na ou não, tinham a chance de contestar ou concordar. Cada dúvida manifestada em um grupo poderia ser interpretada, aproximadamente, como de todos os alunos do grupo? Nas tabelas, apresentamos a proporção do número de vezes em que as perguntas foram feitas ao professor, sem computar quantos alunos compunham o grupo de onde ela provinha.
Por outro lado, o leitor poderia pensar que talvez os alunos desdenhassem a tarefa proposta pelo professor, mas isso com certeza não aconteceu. Os grupos, mesmo os alunos isolados que preferiam trabalhar assim, empenharam-se efetivamente e fazia parte do processo buscarem o professor para resolver as dúvidas que não dirimiam entre si. Quanto aos problemas que não concluíam em aula, tinham a liberdade de consultar o professor nas aulas seguintes. Nestes casos a consulta era mais particular (isto já foi comentado para a questão 9), nos finais das aulas, atraindo muitas vezes outros colegas que tinham também enfrentado dificuldades para resolvê-lo - este registro foi incluído na 
tabela anterior.

\section{Conclusões}

Neste trabalho procuramos identificar e analisar algumas dificuldades relativas à interpretação de enunciados de problemas de Física, especificamente sobre Cinemática de um ponto material, do ponto de vista da Teoria dos Modelos Mentais. Essas dificuldades constituem-se na primeira barreira para o bom desempenho na tarefa de resolvê-los e, neste caso específico, tem sido registrada numa sucessão de 5 semestres letivos, para grupos diferentes de uma mesma disciplina.

A tendência dos alunos em resolver problemas, como os apresentados neste trabalho, é o de resolver um "quebra-cabeça", um jogo com suas "ferramentas" disponíveis (nem sempre com significado para eles) para serem utilizadas numa situação específica. No momento em que este "jogo" exige que eles precisem tomar decisões mais profundas, raciocinar, descrever caminhos ou interpretar dados e resultados, as suas representações internas são requeridas e sua exteriorização nos permite fazer algumas inferências sobre a compreensão que está sendo atribuída ao problema que desenvolvem.

Em vários momentos deste trabalho, foram identificadas como uma das barreiras para a representação de um problema as "concepções alternativas", objetos de estudo em ensino de ciências, especialmente entre 1970 e 1980. Segundo Moreira (1996), os modelos mentais nos permitem entender por que estas concepções são tão resistentes a mudanças: estes modelos são pessoais e funcionais para o indivíduo que os construiu, então modificá-los - no sentido de uma modificação total de uma concepção para outra - não será tarefa trivial. Vosniadou (1994) propõe uma conceituação mais ampla para esta mudança conceitual, como um enriquecimento de modelos prévios e, somente em caso extremo, uma revisão completa destes modelos.

De particular significação para este tema é a maneira como os indivíduos organizam, representam e finalmente utilizam seus conhecimentos. Não há dúvida de que muitas deficiências em solução de problemas podem ser atribuídas à fragilidade de alguns conceitos necessários à tarefa. No caso específico em que os alunos optam por um caminho equivocado, parece-nos que houve falta de "controle", ou seja, os alunos "conheciam" os recursos, mas a fragilidade da interpretação e reconhecimento das informações disponíveis levaramnos a alocá-los indevidamente. Este "controle" inclui decisões executivas sobre planejamento, avaliação, monitoramento e ordenação. Este último aspecto, junto com o conhecimento sobre cognição e as "crenças" do indivíduo, constituem o que usualmente se chama metacognição. Schoenfeld (1985) refere-se ao "sistema de crenças" como a visão do mundo matemático do indivíduo. No nosso caso, incluiríamos também a visão do mundo físico. .

As crenças constituem o conhecimento subjetivo do indivíduo (isto é, não necessariamente correto do ponto de vista científico) a respeito do conteúdo e das tarefas particulares relacionadas. Parece que as crenças modelam atitudes e emoções e dirigem as decisões tomadas durante a atividade matemática na resolução de problemas.

Uma vez superados estes erros envolvendo falta de atenção na leitura, identificação da situação proposta no enunciado, aspectos relevantes e informações que permitem recorrer a modelos que possam solucionar o problema, é necessária uma análise para construir o conhecimento sobre cada estratégia utilizada. Se visamos a aprendizagem significativa, um caminho é o ensino da construção para estas representações - a modelagem.

Segundo Moreira (1996, p.201), os modelos mentais das pessoas podem ser deficientes em vários aspectos, talvez com elementos desnecessários, errôneos ou contraditórios. No ensino, os professores utilizam modelos conceituais e esperam que o aluno construa modelos mentais consistentes com eles, que, por sua vez, devem ser consistentes com os modelos físicos modelados. Este modelos conceituais são os construídos, projetados pelos professores, encontrados nos livros, para facilitar a compreensão de um modelo físico, como os que são tratados nos problemas.

Nossa proposta é encorajar os alunos a interpretar mentalmente e expressar verbalmente as tarefas que lhes são propostas, assim como os resultados numéricos e gráficos que obtêm delas. Um aspecto lingüístico crucial para se entender o raciocínio científico é a explicação, em oposição ao uso de termos técnicos isolados. Dizer que a inversão do sentido de um movimento ocorre sempre que a velocidade se anula não significa que estejamos conscientes do que se passa no movimento: precisamos entender em que condições isso é possível. Esta circunstância envolve a questão da inferência e explicação científicas. Outro aspecto não menos importante é a linguagem matemática.

Segundo o físico, historiador e filósofo da ciência, Pierre Duhem (1949, apud Carey e Spelke, 1994), os cientistas não constroem diretamente do senso comum a compreensão dos fenômenos físicos, mas transladam a linguagem da experiência ordinária para uma descrição matemática do mundo; então eles procuram generalizações e regularidades nesta descrição matemática. Estas generalizações, traduzidas para a linguagem dos objetos do dia a dia, constituirão as leis físicas. O que os cientistas fazem é criar mapeamentos entre a Física e a Matemática. Nersessian (1992) exemplifica este mapeamento entre domínios do conhecimento com os trabalhos de Maxwell e Galileu, em que o raciocínio e compreensão se fazem por meio da construção de modelos 
mentais de fenômenos reais ou imaginários. Da mesma forma, podemos esperar que nossos alunos ultrapassem os núcleos de seus sistemas prévios de conhecimento por meio de mapeamento de diferentes domínios de conhecimento.

Perguntas em forma deliberadamente socráticas podem ajudar nesta tarefa. Como já foi comentado e justificado anteriormente, respostas claras e explicações lúcidas da parte do professor não são suficientes para mudanças nas concepções dos alunos, e beneficiarão a aprendizagem deles menos do que o confronto com contradições e inconsistências que levariam a modificar recursivamente seus modelos mentais.

A presença de concepções semelhantes envolvendo um número significativo de indivíduos nos impulsiona para continuarmos esta pesquisa sobre o papel da modelagem mental na interpretação dos enunciados de problemas de Física. Esta questão, da reincidência de atitudes por parte dos alunos frente aos enunciados dos problemas, ao longo de 5 semestres consecutivos, é um desafio para nosso trabalho na tentativa de reverter este quadro.

Como afirma Moreira (1996, p.230) sobre a Teoria dos Modelos Mentais de Johnson-Laird :

"Possivelmente, este é um referencial promissor, porém mais difícil metodologicamente. A idéia de que as pessoas, ou os alunos no caso, constroem modelos mentais do mundo, i. e., "re-presentam" internamente o mundo externo é atraente. O problema é que é difícil investigar tais modelos. Os modelos mentais das pessoas, ao invés de serem precisos, consistentes e completos, como os modelos cientificos, são, simplesmente, funcionais. Na pesquisa, ao invés de buscar modelos mentais claros e elegantes, teremos que entender os modelos confusos, "poluídos", incompletos, instáveis que os alunos realmente têm. E isso é difícil!"

Pesquisas paralelas, enfocando a resolução de problemas aparentemente semelhantes (Costa e Moreira, 2000), têm acrescentado informações relevantes neste sentido. Acreditamos que exista num caminho viável, que inclui uma reformulação no processo de ensino, envolvendo a modelagem dos enunciados dos problemas de Física, com o objetivo de obtermos melhores desempenhos na aprendizagem. Para isso, temos insistido que nossos alunos desenvolvam uma análise crítica dos enunciados dos problemas que lhes são propostos, abordando conteúdos específicos trabalhados em aula. Esse procedimento tem ajudado a detectar fatores que dificultam a tarefa de resolução de problemas e, ao mesmo tempo, auxiliado a corroborar nossa hipótese de que é possível ajudá-los a modelar mentalmente as situações representadas nos enunciados dos problemas. Uma proposta com este objetivo está nos nossos planos para um próximo trabalho.

\section{Referências}

ARONS, A.B. (1990). A guide to introductory physics teaching. New York: John Wiley \& Sons.

BEER, F.P., JOHNSTON, E.R. (1991). Mecânica Vetorial para Engenheiros - Cinemática e Dinâmica (5 ed). São Paulo: Editora McGraw-Hill.

CAREY, S., SPELKE, E. (1994). Domain-specific knowledge and conceptual change. In: GELMAN, S.A., HIRSCHFELD, L.A. (Eds.) Mapping the mind - Domain Specifity in Cognition and Culture. Cambridge: University Press, p. 474-493, 1994.

COSTA, S.S.C., MOREIRA, M.A. (1996). Resolução de problemas I: diferenças entre novatos e especialistas. Investigações em Ensino de Ciências, Porto Alegre, v.1, n.2, p. 176-192.

(1977a). Resolução de problemas II: propostas de metodologias didáticas. Investigações em Ensino de Ciências, Porto Alegre, v.2, n.1, p. 5-26.

(1997b). Resolução de problemas III: fatores que influenciam na resolução de problemas em sala de aula. Investigações em Ensino de Ciências, Porto Alegre, v.2, n.2, p. 65-104.

( 1997c). Resolução de problemas IV: estratégias para resolução de problemas. Investigações em Ensino de Ciências, Porto Alegre, v. 2, n.3, p. 153-184.

(1998). Modelagem em resolução de problemas: estudo preliminar. Atas do VI Encontro de Pesquisa em Ensino de Física (CD-ROM). Florianópolis, 26 a 30 de outubro, $11 \mathrm{p}$.

(2000). A resolução de problemas como um tipo especial de aprendizagem significativa. Atas do III Encontro Internacional sobre Aprendizagem Significativa, Peniche, 11 a 15 de setembro, p. 243-252.

FONSECA, A. (1964). Dinâmica. Rio de Janeiro: Editora Livros técnicos e Científicos.

GARNHAM, A. (1997). Representing information in mental models. In: CONWAY, M.A.(ed.). Cognitive Models of Memory (1997). Cambridge, MA: The MIT Press.

GIL PÉREZ, D., MARTÍNEZ TORREGROSA, J., SENENT PÉREZ, F. (1988). El fracaso en la resolución de problemas de física: una investigación orientada por nuevos supuestos. Enseñanza de las Ciencias, Barcelona, v. 6, n. 2, p. 131-146.

GRECA, I.M., MOREIRA, M.A. (2000). Mental Models, conceptual models, and modelling. International Journal of Science Education, v. 22, n. 1, p. $1-11$.

HIBBELER, R.C. (1985). Mecânica - Dinâmica. Rio de Janeiro: Editora Campus.

(1999). Mecânica - Dinâmica. (8 ed.). Rio de Janeiro: Livros Técnicos e Científicos Editora S.A.

JOHNSON-LAIRD, P.N. (1983). Mental models. Cambridge, MA: Harvard University Press.

JOHNSON-LAIRD, P.N. (1990). El ordenador y la mente - Introducción a la Ciencia Cognitiva. Barcelona: Ediciones Paidós. 
McDERMOTT, L., ROSENQUIST, M.L., VAN ZEE, E.H.(1987). Student difficulties in connecting graphs and physics: Examples from kinematics. Americam Journal of Physics, v. 55, n. 6, p. 503- 513.

MERIAM, J.L., KRAIGE, L.G. (1999). Mecânica Dinâmica. (4 ed.). Rio de Janeiro: Livros Técnicos e Científicos Editora S.A.

MOREIRA, M.A. (1996). Modelos Mentais. Investigações em Ensino de Ciências. Porto Alegre, v. 1, n. 3, p. 193-232.

MOREIRA, M.A., COSTA, S.S.C. (2000). Pesquisa em resolução de problemas em Física: uma visão contemporânea. In: MOREIRA, M.A., SAHELICES, C.C., VILLAGRÁ, J. M. (orgs.), I Escuela de verano sobre Investigación em Enseñanza de las Ciencias, $A c$ tas, p. 53-82.

NERSESSIAN, N.J. (1992). How Do Scientists Think? Capturing the Dynamics od Conceptual Change in Science. In: GIERE, R.N. (Ed.). Minnesota Studies in the Philosophy of Science, v. XV. Minneapolis: Minnesota Press.

NEWELL, A., SIMON, H.A (1972). Human problem solving. Englewood Cliffs, N.J.: Prentice Hall.

NORMAN, D.A Some observations on mental models. (1983). In: GENTNER, D., STEVENS, A.L. (Eds.). Mental models. New Jersey: Lawrence Erlbaum Associates, p. 7-14.

RESNICK, L.B. (1994). Situated rationalism: Biological and social preparation for learning. In: GELMAN, S.A., HIRSCHFELD, L.A. (Eds.) Mapping the mind - Domain Specifity in Cognition and Culture. Cambridge: University Press, p. 474-493, 1994.

ROSENQUIST, M.L., McDERMOTT, L.C. (1987). A conceptual approach to teaching kinematics. American Journal of Physics, v. 55, n.5, p. 407-412.

SCHOENFELD, A.H. (1985). Mathematical problem solving. Orlando: Academic Press.

STERNBERG, R.J. (1996). Psicologia Cognitiva. Porto Alegre, Artes Médicas Sul (2000). Tradução de Cognitive psychology, Holt, Rinehart and Winston.

TROWBRIDGE, D.E., McDERMOTT , L. (1980). Investigation of student understanding of the concept of velocity in one dimension. American Journal of Physics, v. 48, n. 12, p. 1020 - 1028.

(1981). Investigation of student understanding of the concept of acceleration in one dimension. American Journal of Physics, v. 49, n. 3, p. 242-253.

VOSNIADOU, S. (1994). Capturing and modeling the process of conceptual change. Learning and Instruction, v. 4, p. 45-69.

ZYLBERSZTAJN, A.(1998). Resolução de problemas: uma perspectiva kuhniana. In: VI Encontro de Pesquisa em Ensino de Física, Atas (CD-ROM). Florianópolis, 26 a 30 de outubro, $14 \mathrm{p}$.

\section{ANEXO}

\section{LISTA 1}

1. O movimento de um ponto material é definido pela relação $\mathrm{x}=\mathrm{t}^{4}-3 \mathrm{t}^{3}+\mathrm{t}$, onde $\mathrm{x}$ é expresso em metros e t em segundos. Determinar a posição, a velocidade e a aceleração quando $\mathrm{t}=2 \mathrm{~s}$.

$$
\text { Resp. : }-6 m,-3 \mathrm{~m} / \mathrm{s}, 12 \mathrm{~m} / \mathrm{s}^{2}
$$

2. A relação $\mathrm{x}=\mathrm{t}^{3}-12 \mathrm{t}^{2}+45 \mathrm{t}+18$ (S.I.) representa a posição de um ponto material em função do tempo. Determinar: a) o instante para o qual a velocidade se anula; b) a posição, a aceleração e a distância percorrida ao fim de $5 \mathrm{~s}$.

$$
\text { Resp.: a) } 3 \text { e } 5 \mathrm{~s} \text {; b) } 68 \mathrm{~m}, 6 \mathrm{~m} / \mathrm{s}^{2}, 58 \mathrm{~m}
$$

3. Uma partícula se move ao longo de uma linha horizontal tal que sua velocidade é dada por $\mathrm{v}=\left(3 \mathrm{t}^{2}-\right.$ 6t) $\mathrm{m} / \mathrm{s}$, onde t é o tempo em segundos. Se a partícula está inicialmente localizada na origem 0 , determine: a) a distância percorrida desde $\mathrm{t}=0$ até $\mathrm{t}=3,5 \mathrm{~s} ; \mathrm{b}$ ) a velocidade média e escalar (modular) média durante o mesmo intervalo de tempo; c) a aceleração instantânea em $\mathrm{t}=3,5 \mathrm{~s}$. Interprete todos os resultados com suas próprias palavras.

Resp.: a) $14,1 \mathrm{~m}$; b) $1,7 \mathrm{~m} / \mathrm{s}$ e $4,0 \mathrm{~m} / \mathrm{s}$; c) $15 \mathrm{~m} / \mathrm{s}^{2}$

4. A aceleração de um ponto material é diretamente proporcional ao tempo $\mathrm{t}(\mathrm{a}=\mathrm{kt}$, onde $\mathrm{k}$ é uma constante). No instante inicial $(\mathrm{t}=0)$, sua velocidade é - $5 \mathrm{~m} / \mathrm{s}$ e sua aceleração é nula. Sabendo-se que $\mathrm{v}=$ 0 e $\mathrm{x}=10 \mathrm{~m}$ quando $\mathrm{t}=2 \mathrm{~s}$, escrever as equações que caracterizam o movimento.

$$
\text { Resp: } a=\frac{5}{2} t ; v=-5+\frac{5}{4} t^{2} ; x=\frac{50}{3}-5 t+\frac{5}{12} t^{3}
$$

5. No mesmo instante, dois automóveis A e B, partem do repouso de uma linha de largada. O primeiro possui uma aceleração constante $a_{A}=8 \mathrm{~m} / \mathrm{s}^{2}$, enquanto o segundo possui uma aceleração $a_{B}=\sqrt{2 t^{3}}$ $\mathrm{m} / \mathrm{s}^{2}$, onde $\mathrm{t}$ é medido em segundos. Determine a distância entre os automóveis quando A alcança uma velocidade de $120 \mathrm{~km} / \mathrm{h}$.

\section{Resp.: cerca de $35 \mathrm{~m}$}

6. Um cargueiro move-se a uma velocidade de 8 nós (por curiosidade, 1 nó = 1 milha marítima/hora = $1,852 \mathrm{~km} / \mathrm{h}$ ) quando seus motores são repentinamente parados. Se o cargueiro demora $10 \mathrm{~min}$ para reduzir sua velocidade para 4 nós, obtenha as expressões da distância s, em milhas marítimas, percorrida pelo navio 
e de sua velocidade $\mathrm{v}$, em nós, em função do tempo $\mathrm{t}$ durante este intervalo. Represente-as também através de gráficos. A desaceleração do navio é proporcional ao quadrado da sua velocidade, ou seja, $\mathrm{a}=-\mathrm{kv}^{2}$.

Resp.: $v=8 /(1+6 t) ; s=4 / 3 \ln (1+6 t)$

7. O movimento de um ponto material é dado pela função horária da posição: $\mathrm{x}=2 \mathrm{t}^{3}-15 \mathrm{t}^{2}+24 \mathrm{t}+4$ (S.I.). Determine: a) o instante em que a velocidade se anula; b) a posição e a distância total percorrida até quando a aceleração se anula.

Resp.: a) $1 \mathrm{~s}$ e 4s; b) $1,5 \mathrm{~m}$ e $24,5 \mathrm{~m}$

8. A aceleração de um ponto material é $\mathrm{a}=-\mathrm{k} / \mathrm{x}$.
Determinou-se experimentalmente que $\mathrm{v}=3 \mathrm{~m} / \mathrm{s}$ e $\mathrm{a}=$ $-1,2 \mathrm{~m} / \mathrm{s}^{2}$, quando $\mathrm{x}=500 \mathrm{~mm}$. Obter a) a velocidade quando $\mathrm{x}=750 \mathrm{~mm}$ e b) a posição do ponto para a qual a sua velocidade é nula.

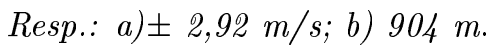

9. A velocidade de uma partícula que atravessa um líquido para baixo é medida em função de seu deslocamento $\mathrm{s}$ por $\mathrm{v}=(125-\mathrm{s}) \mathrm{mm} / \mathrm{s}$, onde $\mathrm{s}$ é dado em mm. Determine: a) a aceleração da partícula quando ela está localizada a $100 \mathrm{~mm}$ a partir da sua posição original; b) a distância que a partícula percorre até parar; c) o tempo necessário para ela parar.

Resp.: a) $-25 \mathrm{~mm} / \mathrm{s}^{2}$; b) $125 \mathrm{~mm}$; c) $\infty$ 